\title{
EL LENGUAJE MULTIDISCIPLINAR DE VINCENZO CONSOLO
}

\author{
Carolina Martín López \\ Universidad de Málaga \\ cimartin@uma.es
}

\begin{abstract}
RESUMEN: La contribución propone un acercamiento a la narrativa de Vincenzo Consolo a través de las frecuentes citas pictóricas, escultóricas, y en menor medida cinematográficas, fotográficas y musicales, que el autor emplea en un proceso de verticalización de su escritura. Consolo recurre al imaginario plástico, procedente de diferentes disciplinas artísticas, y a la evocación de composiciones musicales o cinematográficas cuando expresivamente no es posible sólo la palabra, cuando ésta necesita del apoyo icónico para que una obra pueda ser transmitida de forma armónica, expresando toda su semanticidad, abriendo un amplio abanico de significados polisémicos. El recurso al arte figurativo, cinematográfico y musical no sólo sirve a Consolo de inspiración en el trazado de la identidad de sus personajes, sino que ayuda a la reevocación de los momentos históricos, reforzando su permanencia en la memoria.

PALABRAS CLAVE: Vincenzo Consolo, lenguaje multidisciplinar, intermedialidad, interdiscursividad.
\end{abstract}

\section{THE MULTIDISCIPLINARY LANGUAGE OF VINCENZO CONSOLO}

ABSTRACT: The essay proposes an approach to the narrative of Vincenzo Consolo through frequent pictorial and sculptural quotes, and to a lesser extent cinematographic, photographic and musical ones, which the author draws on in a process of verticalization of his writing. Consolo resorts to the imaginary plastic, coming from different artistic disciplines and to the evocation of musical or cinematographic compositions, when expressively the word does not render, when this needs the iconic support for a work to be transmitted in a harmonious way, expressing its entire semanticity, opening up a wide range of polysemic meanings. Drawing on figurative, cinematographic and musical arts, not only provides Consolo with inspiration on the identity path of his characters, but that helps the revocation of the historical moments, reinforcing their place in memory.

KEYWORDS: Vincenzo Consolo, multidisciplinary language, intermediality, interdiscourse.

Recibido: 01/04/2015. Aceptado: 14/04/2016 
Uno de los conceptos teóricos que resultan más reveladores a la hora de aproximarse en clave interpretativa a la escritura de Vincenzo Consolo, constituyéndose en valor determinante de la coherencia macrotextual de toda su narrativa, es el de intermedialidad ${ }^{1}$, entendida en este trabajo como la referencialidad en un texto literario a otras manifestaciones artísticas (Rajewski 2005: 44): pintura, escultura, cinematografía, fotografía y música. Aunque en el desarrollo de este análisis se toma en consideración un extenso corpus de obras consolianas, se dedica más espacio (las páginas iniciales) al Sorriso del ignoto marinaio porque además de que gran parte del entramado textual de esta novela, por encima del resto de la producción literaria del autor, se construye sobre la base de una obra pictórica, el cuadro Ritratto d'ignoto de Antonello da Messina, es en donde podemos encontrar un mayor número de alusiones a obras plásticas, concretamente a nueve grabados goyescos.

A pesar de que algunos comentaristas y el propio Consolo se hayan referido al hecho de que el lenguaje iconográfico ha estado siempre presente en su obra desde sus textos de exordio, y sobre todo en La ferita dell'aprile ${ }^{2}$, no se puede hablar de una alusión explícita a una obra plástica determinada hasta Il sorriso dell'ignoto marinaio, publicada en 1976, en donde el cuadro de Antonello da Messina, conservado en el museo Mandralisca de Cefalù, no sólo da título a la novela consoliana -con una variante que le otorga identidad al modelo representado- sino que se convierte en el motor de todo el desarrollo narrativo del libro. El propio autor, recabando en su memoria personal, cuenta su experiencia con el retrato de Antonello en la entrevista recogida en Fuga dall'Etna:

Ho visto quel quadro in anni lontani, non riesco a ricordare quando. Da ragazzino, certo. Lo vidi poggiato su un cavalletto, senza cornice, vicino a una finestra, illuminato dalla luce solare [...] Il personaggio effigiato mi apparì familiare $\mathrm{e}$ insieme lontano, enigmatico. Era uno che "somigliava" a tante persone che avevo conosciuto o che mi vedevo intorno. Quegli occhi, quel sorriso ironico, quella forza realistica, concreta dell'aspetto [...], rappresentava certo l'archetipo dell'uomo siciliano, con tutte le componenti etniche e culturali dietro, giunto, dopo la tempesta della giovinezza o la precarietà sociale, alla sicurezza della maturità, della cultura e del censo. (Consolo 1993a: 41-42).

1. Un estudio claro y conciso sobre el interesante debate académico en torno al término "intermedialidad" y su reflexión teórica, desde que fue empleado por primera vez en 1966 por el artista estadounidense Dick Higgins hasta la actualidad, es el realizado por Cubillo (2013).

2. Algunas páginas de esta primera novela de Consolo, publicada en 1963, están escritas a partir de percepciones visuales, cromáticas, y el pasaje en el que se describe la erupción del Etna remite, sin nombrarlo, al cuadro Fuga dall'Etna de Renato Guttuso y también al Guernica (Cuevas 2005: 65-66). 
En las palabras apenas expuestas se condesa toda la trama narrativa, el significado de la novela del Sorriso: la realización del viaje existencial que el protagonista, el barón de Mandralisca, deberá emprender para parecerse al final de la novela a la imagen del retrato, un hombre que sonríe irónicamente porque ha alcanzado la madurez de analizar los hechos objetivamente, con distanciamiento, y de encontrar su posición de intelectual en el mundo.

Mandralisca entra en crisis porque se encuentra ante la realidad trágica y dramática de la revuelta campesina de Alcara Li Fusi³ , y tomando conciencia de las necesidades populares, intercede por la causa de los rebeldes que están a punto de ser condenados a muerte y escribe cartas al presidente del tribunal, Giovanni Interdonato (Consolo 1993a: 45).

El retrato, contemplado en clave literaria por el escritor, se asemeja además no sólo al Mandralisca que ha tomado conciencia, sino a Interdonato y al propio autor puesto que la existencia de un único punto de vista narrador-Mandralisca es traducible a la identificación Mandralisca-Consolo, que no en vano, además, se deja retratar en una ocasión como el desconocido del cuadro, con la misma indumentaria y la misma gestualidad, como puede verse en la figura número dos del libro de Vincenzo Pascale (2006). Y en este juego de los parecidos, se va delineando y perfilando a su vez, en definitiva construyendo, la identidad de todos los personajes que, encontrándose ante el cuadro de Antonello, contemplan al desconocido representado.

A través de esta misma imagen, Consolo va componiendo asimismo un cuadro histórico-moral del periodo del Risorgimento (de ocho años en concreto, de 1852 a 1860), que a su vez es el reflejo de su historia contemporánea, de los años

3. Se hace referencia a una revuelta campesina que tuvo lugar el 17 de mayo de 1860, con efectos sangrientos, en Alcara Li Fusi, pueblo siciliano de la provincia de Messina cercano al del autor (Sant'Agata di Militello). Los braceros y campesinos, desesperados ante las vejaciones e infrahumanas condiciones de vida a las que eran sometidos por los terratenientes, y creándose expectativas de justicia social ante el inminente desembarco de los garibaldinos en la isla, asaltaron un edificio público (el Casino dei civili) causando la muerte a once personas. Tras cuarenta días de saqueos, incendios, devastación de cosechas y apropiación de casas y de fincas que siguieron a la revuelta, actos todos ellos dirigidos por los cabecillas revolucionarios que se hicieron con el poder del pueblo, el coronel garibaldino Giovanni Interdonato apresó a algunos de los rebeldes y, después de un rápido proceso, éstos fueron ajusticiados. Este episodio histórico, al que la historiografía no ha prestado mucho interés, ocupa el centro neurálgico de la novela consoliana, abriendo un debate entre el carácter más o menos popular del Risorgimento y la relación existente entre los acontecimientos históricos y la realidad de los estratos sociales mas bajos de la población meridional. Un interesante y esclarecedor artículo sobre los motivos que impulsaron a la revuelta de Alcara Li Fusi es el de Pietro Siino (1980). El periodo histórico en cuestión ha sido tratado por Denis Mack Smith (1970). 
setenta, señalada por el compromiso histórico y por la abdicación de los intelectuales de izquierda a la función revolucionaria. Vemos, pues, como el recurso al arte figurativo, aparte de servir de inspiración en el trazado de la identidad de los personajes, ayuda a la reevocación de los momentos históricos, reforzando su permanencia en la memoria. No casualmente el capítulo del Sorriso dedicado a una relectura de los dibujos de Goya se titula Memoria. En él, Consolo, como ya ha señalado la crítica en unas páginas dedicadas exclusivamente al análisis de la relación Consolo-Goya (Pascale 2006: 83-102), toma prestados nueve títulos ${ }^{4}$ de los grabados de Los desastres de la guerra, para sintetizar las dramáticas escenas de horror y muerte que rememoran textualmente las vividas en Alcara Li fusi. Así, por ejemplo, describe Mandralisca el estado de los cadáveres abandonados en la plaza donde fueron asesinados:

Che passa? Passa che qui è passato il finimondo.

Nella calda piazza desolata orridi morti addimorati rovesciansi dall'uscio del Casino e vi s'ammucchiano davanti, sulle lastre, uomini fanciulli e anziani. Pesti, dilacerati, nello sporco di licori secchi, fezze, sughi, chiazze, brandelli, e nel lezzo di fermenti grassi, d'acidumi, lieviti guasti, ova corrotte e pecorini sfatti. Sciami e ronzi di mosche, stercorarie e tafàni.

Era il meriggio pieno, senza fine.

Tutto è sconvolto. Non si può guardare. (Consolo 2004: 123).

Otras veces el título goyesco, que Consolo, como hemos visto en el ejemplo anterior, traduce a su lengua y pone siempre en cursiva, sirve de preámbulo a la textualización de las imágenes que el título del cuadro le sugiere, haciendo posible un diálogo entre pintura y escritura:

Che si può far di più?

Di più può far il vulturùne.

Le ali aperte per tre metri e passa, stese le zampe con gli artigli curvi, grasso, enorme piomba a perpendicolo dall'alto come calasse dritto dall'empireo.

L'avvoltoio carnivoro si posa sopra i morti putrefatti: affonda il rostro, scava, un colpo vigoroso della testa, e strappa, da ventre o da torace, un tocco. S'erge, e vola via con frullìo selvaggio. (2004: 124).

4. Todo está revuelto. No se puede mirar; ¿Qué más se puede hacer?; Así ocurrió; Extraña devoción; ¿Qué vocerío es este?; Madre infeliz; Lamentos vanos; Sí, son de otro linaje y Carretadas al cementerio. 
Y el tercer capítulo del Sorriso, titulado Morti sacrata, se abre con el íncipit Tristes presentimientos de lo que ha de acontecer, extraído también de Los desastres de la guerra, con la intención de que los acontecimientos que en esas páginas concretas del libro están por narrarse (la preparación de las armas que se utilizarán en la revuelta de Alcara, el anunciamiento del desembarco de los garibaldinos en la isla y el estupro que comete el ermitaño loco, que viola a una muchacha muerta) presagien el ambiente de sangre y muerte en el que se desarrollará la trágica revuelta. En esta ocasión, además, Consolo traspone al texto la imagen más o menos exacta que Goya representa en el dibujo: un fraile con el hábito desgarrado y el rostro descompuesto que implora a Dios arrodillado, mirando al cielo con los brazos extendidos en cruz. El ermitaño loco que crea Consolo, después de haber practicado el coito con el cadáver de la muchacha, corre hasta el presbiterio de la iglesia de la plaza y allí "Crolla in ginocchio avanti al popolo, larghe le braccia e stralunìo d'occhi verso l'alto" (2004: 78). Mientras cae de rodillas, declama en silencio las palabras del íncipit con algunas variaciones: "Triste presentimento d'amari accadimenti mi stricia nel cuore e nel cervello” (2004: 78).

Como puede deducirse de lo apenas expuesto, las imágenes textuales consolianas creadas alegóricamente a partir de los dibujos de Goya no son menos cruentas y terroríficas que las representadas por el pintor con objeto de reflexionar sobre los tumultos sociales originados por la guerra de la independencia española. Vincenzo Pascale (2006) explica la inclusión narrativa de estas referencias pictóricas basándose en un concepto expresado por Américo Castro (1996) según el cual, los hechos históricos no ocurren solamente en un lugar o en un determinado año, sino principalmente en la conciencia colectiva. No hay duda de que la construcción narrativa consoliana opera sobre la similitud histórica y social de los hechos ocurridos en Alcara Li Fusi y los episodios bélicos españoles, pero la intención de esta transposición narrativa de las imágenes goyescas responde asimismo a la plasmación pictórica de los sentimientos y actitudes universales que Goya consigue transmitir, que hacen que sus grabados adquieran un tono de atemporalidad, de universalidad, prestándose por ello a ser recurrentes alegóricos en cualquier obra contemporánea, al poder explicar la realidad del presente a través de la memoria del pasado. Cuando años más tarde, en L'olivo e l'olivastro, Consolo pretende dejar constancia de la devastación de Palermo tras el fracaso de los programas políticos y el poder de la mafia, hallará también la manera de hacerlo a través de las referencias a los caprichos goyescos, a las pinturas negras y a la “desesperada” Quinta del sordo (Consolo 1994b: 125). De igual modo, observa Salvo Puglisi (2008: 296) y anteriormente Giuseppe Traina (2001: 32), operará Consolo en Catarsi cuando al evocar la muerte de García Lorca, junto a la de otros 
poetas -Vladimir, Pasolini- víctimas de la violencia de todos los tiempos, alude a una imagen de Los fusilamientos de Goya: "[...] Federico / tra gli ulivi e i cardi (splendeva, / contro il nero dei fucili, dei colbacchi / la sua camicia bianca, splendeva / nella notte lo sciame nella lampada di lucciole)" (2002: 18). En el marco de las relaciones intratextuales, aparte de las alusiones goyescas, resultan significativas también, como refiere Cuevas (2005: 71-72), las citaciones pictóricas que remiten a Caravaggio, anunciado en Retablo, con una breve descripción de la luz que hace recordar la del pintor, y cuya presencia llena el capítulo XI de L'olivo e l'olivastro con la llegada de Caravaggio a Siracusa. Los trazos caravaggescos reaparecen levemente también como apoyo descriptivo en Lo spasimo.

Consolo recurre a la imagen cuando expresivamente no es posible sólo la escritura, cuando ésta necesita del apoyo icónico para que una obra pueda ser transmitida de forma armónica, expresando toda su semanticidad. Y así lo manifiesta personalmente él mismo autor en una entrevista concedida a Giuseppe Traina: "Credo che ci sia un bisogno di equilibrio tra suono e immagine, come una sorta di compenso, perché il suono vive nel tempo, invece la visualità vive nello spazio. Cerco di riequilibrare il tempo con lo spazio, il suono con l'immagine” (Traina 2001: 130). Para Consolo, como manifiesta en otra ocasión (2001c), la escritura es ante todo sonido, palabra escrita para ser escuchada ${ }^{5}$, de ahí su acercamiento al registro poético, a la sonoridad de su prosa narrativa, que intenta equilibrar con una parte visiva.

Así pues, siendo el imaginario plástico un material de constante trabajo en la práctica escritural de Consolo, encontramos citas iconográficas en la casi totalidad de su obra, siendo incluso el título y la estructura compositiva de uno de sus libros una tabla pictórica, concretamente un tríptico, Retablo, compuesto por tres cuadros narrativos: Oratorio (primer capítulo), en donde un fraile del siglo XVIII, llamado Isidoro, narra su huida del convento por el amor que siente por Rosalía, y cómo se pone al servicio del pintor ilustrado Fabrizio Clerici; Peregrinazione (segundo capítulo), constituido por el diario de viaje por Sicilia de Clerici 6 , que rechazado

5. La musicalidad poética se ha convertido en uno de los signos relevantes e identificativos de la escritura consoliana, tanto es así que una recopilación de ensayos sobre la narrativa de este autor lleva como título La parola scritta e pronunciata (Adamo 2006) e incluye un cd con fragmentos de las obras de Consolo, leídos por el propio autor.

6. Este personaje está inspirado en el pintor contemporáneo Fabrizio Clerici, amigo de Sciascia y de Consolo, para el que ilustra, además, con cinco dibujos la primera edición de Retablo. Sobre este tema y los motivos pictóricos de las portadas de los libros de Consolo, con comentarios pertinentes al diálogo pintura-escritura que aquí se comenta, cfr. Cuevas (2005: 67-68, 70). 
por su amada Teresa Blasco ${ }^{7}$, viaja para olvidarla; y Veritas, declaración de amor de Rosalía, que confiesa en un escrito, que ocupa todo el tercer capítulo, que siempre, aunque lo haya mantenido en secreto, ha estado enamorada del fraile Isidoro.

Retomando el tema del alcance metafórico de los títulos que elige Consolo para sus obras, incitando con ello a unas claves interpretativas más cercanas a la contemplación de un cuadro que a la lectura de una novela, no se puede dejar de mencionar Lo spasimo di Palermo, que hace referencia a un cuadro de Rafael, Caduta sulla via del Calvario o Lo spasimo di Sicilia, en el que el pintor reflexiona sobre la imagen de la Virgen, que resiste al dolor intentando, en un último y desesperado esfuerzo, ayudar al hijo caído. Esta cita iconográfica presente en el título consoliano tiene el mismo alcance significativo que la inclusión, en el último capítulo, de las primeras líneas de la partitura del Stabat Mater de Emmanuele d'Astorga; composición que medita a su vez sobre el sufrimiento de la madre de Jesús durante la crucifixión y la Pasión de Cristo -"stabat mater dolorosa juxta crucem lacrimosa”" (Consolo 2000b: 125)-. La presencia de ambos discursos, el iconográfico de Rafael y el musical de Emmanuele d'Astorga, que dilatan hasta su más alta dimensión la expresión del dolor, crean un nexo simbólico entre la Virgen, presente en el camino del Calvario, y la madre del juez asesinado por la mafia, personaje inspirado en Borsellino. Resulta evidente, además, el carácter cristológico que envuelve al magistrado, víctima de la barbarie de los mafiosos, mártir por desear restablecer, como el propio autor escribe en Lo spasimo di Palermo, "il potere dello Stato, il rispetto delle sue leggi” (2000b: 129).

La colocación de ambas citas en la novela, la pictórica y la musical, no es fortuita a la técnica narrativa de Consolo, que busca siempre un amplio abanico de significados polisémicos. La referencia al cuadro de la escena del calvario es situada a modo de íncipit, mientras que las primeras notas del Stabat Mater suenan en el éxplicit, poco antes de que una explosión acabe con la vida del magistrado. El lenguaje musical presagia por ello el narrativo, es decir, condensa todo lo que la palabra contará después, de la misma manera que el lenguaje iconográfico empleado en el título sirve de presentación al sacrificio, a la muerte que posteriormente se verá cumplida en la escritura. (Resulta altamente significativo cómo Consolo recurre a otra composición musical, concretamente al Requiem

7. Teresa Blasco es un personaje histórico, protagonista de las crónicas del siglo XVIII de Milán. Casada con Cesare Beccaria, es la abuela materna de Alessandro Manzoni. Giovanni Albertocchi (2005) dedica un artículo entero al estudio de este personaje en su doble vertiente de ficción y realidad.

8. El autor del texto latino es Jacopone da Todi. El texto, a petición del músico Matteo D’Amico, fue traducido al italiano por Consolo con objeto de la composición de un Oratorio. Son varios los textos que Consolo escribió para música, entre ellos L’ape iblea; (cfr. Puglisi 2008: 417-418). 
por le vittime della mafia9 cuando en L'olivo e l'olivastro, el protagonista, recorriendo la autopista que lleva al aeropuerto de Punta Raisi de Palermo, pasa por el lugar donde fue asesinado Falcone).

Con respecto a Lo spasimo di Palermo, hay que añadir que algunos comentaristas se han referido también al paratexto de portada que aparece en la primera edición del libro: un detalle del cuadro de Rafael en el que aparece "un rostro petrificado en un grito", el mismo grito, mudo, de horror con el que se cierra la novela "ante la evidencia de la crueldad" (Cuevas 2005: 70); grito que es extensible, además, a toda la novela de Consolo (Traina 2001: 107); y no sólo a Lo Spasimo, sino también a Nottetempo, casa per casa en donde los gritos del protagonista, que está sumido en una profunda afasia, son los únicos sonidos fonéticos que es capaz de emitir, hasta que, hallado el sentido de su existencia, vuelve a recuperar la voz.

Esta novela consoliana, Nottetempo, como las anteriores que se han referido, entabla un diálogo interdiscursivo con otras disciplinas artísticas, entre las que abundan las referencias pictóricas. Por ejemplo, cuando Petro, el protagonista, está en los subterráneos de la torre, descubre a un ángel de mirada de luz cegadora, que no es sino una intersección iconográfica, según refiere Rossend Arqués (2005: 91), de uno de los ángeles representados en los mosaicos de la Catedral de Cefalù y la imagen del escriba del grabado de Durero Melancolia I; aunque el ángel de Durero (precisa el crítico) es negro y el de Consolo, blanco. Pero quizás éste sea el único punto disimétrico entre las dos imágenes, puesto que todos los objetos que aparecen en la descripción de Consolo están presentes en la obra de Durero: la esfera, el compás, la clepsidra, la balanza y la misteriosa luz crepuscular, que reproduce la de un espíritu que no es capaz de ahuyentar los pensamientos tenebrosos ni llevarlos al "mundo de la luz". El contenido conceptual de esta imagen es doble, como describe claramente el narrador consoliano: "l’ora della luce bianca, della luce nera, sospesa e infinita” (Consolo 1994a: 65).

Todos estos elementos iconográficos empleados por Durero y Consolo: el tintero, la pluma, los instrumentos relacionados con la geometría, la aritmética y la medida del tiempo son objetos que anuncian la escritura, pero sólo la pre-

9. Se trata de una obra que nace por iniciativa del compositor Marco Tutino, aunque en la partitura contribuyeron diversos compositores. A Consolo se le encargó la traducción al italiano del texto litúrgico original en latín (Dies Irae). En una entrevista que Consolo concedió a Roberta Visco, éste declaró que la traducción-reescritura fue una ardua labor, que se sintió incapaz de hacerlo dada la belleza del texto original, pero añadió "mi sembrava giusto, doveroso farlo. Ormai per le tragedie di Palermo tutte le parole sono consumate. C'è il rischio di cedere al silenzio, che terrifica e blocca" (Consolo 1993b). Se reproduce esta cita extraída del paratexto del Requiem, concretamente de la solapa de la portada, porque es altamente pertinente al tema de la afasia, sobre el que se seguirá insistiendo, al estar presente en gran parte de la obra consoliana. 
sagian puesto que el escriba alado del dibujo a pesar de estar rodeado de todos estos utensilios de trabajo creativo, mira hacia el interior, hacia una lejanía vacía, cavilando melancólicamente con la sensación de no llegar a nada. Es necesaria la materialización de la escritura, que este genio alado parece no conseguir, para pasar a un estadio superior del lenguaje y del conocimiento. Sólo la luz, metáfora de la escritura y del conocimiento, ayuda a entender el mundo, pero para llegar a ella es necesario asumir toda la memoria dolorosa, la desesperación, conocer todas las casas (de ahí parte del título, casa per casa ${ }^{10}$ ) y las cosas, las piedras, las paredes, leer todos los libros..., asistir a la degradación de las tradiciones, de las costumbres, los mitos, a la depravación de los presuntos liberadores del espíritu, a la violencia criminal de los fascistas. Se debe atravesar, como Petro, el silencio y el grito para llegar a la palabra (Arqués 2005: 91-92).

En las páginas de Nottetempo destinadas a expresar la impotencia hacia la palabra, hacia la escritura, surge, pues, la metáfora de la luz como posibilidad de recuperación de una memoria mítica que vuelve a recrear y a iluminar mundos arcaicos, sepultados, gracias a los cuales los nombres, abandonada la afasia inicial, los gritos y los aullidos, vuelven a ser renombrados adquiriendo un verdadero sentido.

Otro elemento si no constante, sí de una considerable presencia en la escritura consoliana, es el referente a las figuras escultóricas, procedentes algunas de ellas del imaginario mítico de la Antigua Grecia, y que Consolo convierte en instrumentos de su verticalidad expresiva, en metáforas narrativas de lo que realmente quiere decir. En Il sorriso, por ejemplo, nos encontramos con el busto de Coré (Perséfone) petrificado en una estatua de mármol que Interdonato lleva a Mandralisca, de Lipari a Cefalú, como presente del boticario Cardinale, el cual precedentemente ya le había vendido el retrato del desconocido de Antonello da Messina. Coré, símbolo de la fecundidad, relacionada con el mundo materno -no en vano, como también refiere Traina (2001: 64), los dos “esbirros” encargados de controlar la mercancías de la nave, la confunden con una Virgen- representa a Sicilia, a la tierra madre. Y será, además, el mismo Mandralisca el que al contemplar la escultura, diga: "se io debbo pensare a un'immagine dell'Italia Libera e Unita, è a una statua così che io penso...” (Consolo 2004: 52). La dimensión significativa de esta figura se ve más reforzada en el contexto al ser entregada en

10. El título Nottetempo, casa per casa hace también referencia al tiempo nocturno, oscuro e irracional del periodo histórico en el que se desarrolla la novela y a las incursiones inesperadas que la policía fascista llevaba a cabo casa por casa (Vazzana 1994: 35). De hecho, en la última parte del libro se produce una irrupción fascista en la casa de Marano, situación que Consolo utiliza también en Un giorno come gli altri (2001a: 402-403) y que no puede dejar de recordarnos a la que sufre en su estudio el abogado Di Blasi en el Consiglio d'Egitto de Sciascia. 
casa de la familia Mandralisca junto con un mantel (regalo de Catena, la novia de Interdonato, a la sobrina del barón) en el que hay bordado un árbol que, como confirmará Interdonato, representa a Italia, con cuatro naranjas que simbolizan los cuatro volcanes de las dos Sicilias -el Vesubio, el Etna, Stromboli y Vulcanodesde donde brotará la revolución (Consolo 2004: 53).

La estatua de Coré, empleada como hemos visto en uno de los primeros libros de Consolo, abrirá paso en novelas sucesivas a una serie de frecuentes alusiones escultóricas, procedentes de los hallazgos encontrados entre las ruinas de Selinunte, de Segesta o de Mozia. Este interés de Consolo por los vestigios arqueológicos sicilianos de antiguas civilizaciones (huellas de un pasado cultural que ayuda a entender el presente de la isla) será el hilo conductor del relato Le pietre di Pantalica, que da título al libro homónimo, aunque las apariciones de estos testimonios artísticos de un tiempo remoto están presentes también en L'olivo e l'olivastro y en obras precedentes, como Il sorriso o Retablo. En esta última novela citada, una estatua de un efebo griego (un atleta, un auriga o un dios) hallada por unos campesinos que no reconocen su valor, es vendida por una suma irrisoria al pintor Clerici, quien se embarcará con ella en Birgi con la intención de arribar al puerto de Palermo, pero en una tempestad inesperada, que a punto está de hacer naufragar la nave, la estatua, para contrarrestar peso, es lanzada al mar. Traina (2001: 80) ve una cierta relación entre este episodio y "la morte per acqua" del fenicio Phlebas evocado por Eliot y cita textualmente algunas palabras de Clerici: “tu, squisita fattura d’uomo, fiore d’estrema civiltà, estrema arte, tu, come ogn'arte, non vali la vita, un fiato del più volgare o incolto, più debole o sgraziato uomo” (Consolo 2000a: 126).

Consolo hace emprender a Clerici el mismo viaje por el interior de una Sicilia mítica que él realizó alejándose de Milán, y, como él, su personaje se encuentra con una tierra repleta de belleza y de riquezas humanas, pero donde impera la violencia, el horror, la impostura y la barbarie cultural, en donde el pasado corre el riesgo de ser cancelado por el Poder o la ignorancia.

En otras ocasiones el lenguaje metafórico consoliano dialoga con el arte de la cinematografía, con la séptima musa, palabras estas últimas, además, con las que Consolo da nombre al hotel donde se aloja Gioacchino, el protagonista de Lo spasimo di Palermo. Este personaje "aprovecha un viaje a París para ver determinadas secuencias de una película de su infancia, quemadas por la avería de la máquina de proyección, que adquieren entidad narrativa como metáfora de un devenir fracturado” (Cuevas 2005: 66). Así efectivamente, lo cuenta la voz del narrador: "In quel taglio, quel vuoto, in quel buio sospeso erano i fotogrammi segreti della sua storia, della sua vita oscura e inconclusa, della frana, delle colpe sepolte e 
obliate" (Consolo 2000b: 47). Aunque Consolo focalice externamente este episodio narrando en tercera persona, subyace en la cita un claro autobiografismo, como se desprende tras la lectura de unas páginas tituladas "La cuna del sogno", que el autor escribe en relación a la película de Giuseppe Tornatore Nuovo cinema paradiso, en donde yuxtapone dos recuerdos de su infancia-adolescencia: el de los rollos de película incendiados en el cinematógrafo del colegio de los salesianos y el de la pólvora de los cartuchos que los soldados americanos dejaban en los campamentos al alcance de los niños para sus juegos prohibidos (Consolo 1990b: 168).

La misma idea de los fotogramas fragmentados le sirve a Consolo para explicar, en la contribución apenas referida, el modo de proceder de la memoria, cuyo movimiento se asemeja a las secuencias, a veces aparentemente inconexas, de una proyección cinematográfica: "La memoria, i ricordi. Quanto più lontani nel tempo, tanto più frammentati, intermittenti come i sogni, come fotogrammi isolati di un film: la memoria come il sogno; il sogno come il film” (1990b: 167).

En una crónica titulada Don Luigi e il suo paese, recogida recientemente en una recopilación de ensayos de publicación póstuma a la muerte de Consolo, (fallecido en enero de 2012), el autor construyó una escena cinematográfica para narrar un suceso real: el secuestro por unos bandidos de Luigi Corleo, recaudador de impuestos de la localidad siciliana de Salemi. Consolo, como él mismo manifiesta, recurre al lenguaje cinematográfico, y explícitamente a la voz de un director de cine, por necesidad de pasar a la ficción cuando la realidad es tan fuerte que se convierte en hiperrealidad increíble o insoportable: “"Alt. Bisogna rifare la scena» si poteva udire, al megafono dalla voce di un regista. Che il bisogno del passaggio alla finzione, alla scena, si ha quando la realtà è talmente forte da rovesciare in iperrealtà incredibile o insopportabile” (2013: 156).

Pero no sólo el lenguaje cinematográfico está presente en la obra consoliana; también las imágenes captadas por una cámara fotográfica son decisivas en la construcción narrativa de algunas de sus páginas. En I linguaggi del bosco, relato autobiográfico que forma parte de Le pietre di pantalica, se construye un episodio de la infancia del protagonista (las vacaciones estivales de 1938 en el bosque de la Miraglia), partiendo de la descripción de un par de fotografías de la niñez que activan los recuerdos del pasado ${ }^{11}$ :

11. Aparte de este relato y de otra serie de episodios incluidos en esta misma obra y en La ferita dell'aprile, de crucial importancia para la reconstrucción de la biografía personal del autor, es muy difícil, a causa además de la desarticulación narrativa de los textos consolianos, por no decir inabarcable dentro de los límites de estas páginas, delimitar todos los espacios escriturales en donde el autor se aproxima al género de la autobiografía. 
Queste le due foto. E ora cercherò di allargarne, di dilatarne l'esigua superficie di cm $8 \times 13$, di animarne le scene, di muovere camion e personaggi, toglierli dalla loro stampata fissità, d'aggiungere qualche altro colore alla loro bicromìa di bianco e nero. Di dire d'altre scene, d'altri personaggi e linguaggi che nel bosco vidi e udii. Di raccontarli. (1990a: 150).

Como testimonia el propio autor en líneas precedentes de la misma narración (1990a: 148), yuxtapone, enlaza en esta ocasión dos lenguajes absolutamente diferentes, inconciliables, el fotográfico y el literario, para construir, a través de la memoria, una cierta realidad, una cierta historia. Para Consolo, como declara en una ocasión a Ferruccio Parazzoli (1998: 29), la fotografía es un instrumento de memoria y la memoria es el pozo profundo del que el escritor debe extraer las palabras. En L'olivo e l'olivastro el escritor vuelve a reincidir en la cita fotográfica -aunque con distintos matices semánticos que en Le pietre di Pantalica - cuando para reconstruir la historia autobiográfica de su madre anciana, alejada de él y de todos los hijos, recurre al recuerdo de una imagen impresa en una revista americana, con el propósito de que este recurso le ayude a expresar el grado de densidad de un cierto sentimiento entre melancolía, culpa y fatalidad que la contemplación de su madre le está produciendo:

Gli venne in mente una sequenza fotografica [...] d'un figlio che aveva fissato sulla lastra le immagini del vecchio padre che moriva. [...] Pensava ch'era stato lui per primo a rompere gli ormeggi, allontanarsi, via per tanto tempo. Cosa credeva? Che quella donna, sua madre, fosse rimasta sempre lì, uguale, come il giardino, le barche, le isole, con il ricordo di lui sempre acceso? Il dolore sempre vivo per gli altri figli andati, scomparsi? Aveva mollato pure lei (ma come, quando?) e s'era messa a camminare per la sua strada. Voleva annullare quel tempo, ritornare, lui, al punto della partenza, far tornare lei, vecchia Euridice, di là dall’ombra dell’oblìo? (1994b: 120).

La referencia iconográfica, de asidua frecuentación a lo largo de la obra consoliana, sobre todo la relativa a las artes plásticas, evidencia en definitiva el procedimiento de construcción textual que da cohesión a la totalidad de la producción narrativa de este autor, tejiendo una red de conexiones intratextuales que van más allá de la mera metaforización descriptiva, al poner en contacto dos procesos creativos: uno previo, el del lenguaje iconográfico, que es aludido a través de otro proceso creativo: el del texto literario. La intermedialidad artística, la conexión entre texto literario y texto icónico se convierte en la obra de Consolo en una necesidad de equilibrio entre la sonoridad de la palabra y la visualidad de la imagen, que no responde sólo a un claro propósito de funcionalidad estética, de densificar 
el lirismo de algunas páginas o verticalizar su forma de expresión, sino que lleva a la apertura de un extenso ámbito semántico no del todo explorado, no terminado de descifrar, por lo que el camino para la crítica interpretativa no deja de ser amplio e interesante. Consolo construye sus relatos a partir de percepciones visuales que le hacen reflexionar sobre su propia experiencia escritural, sobre la naturaleza de su escritura, cobrando por ello también un evidente sentido metaficcional. El recurso interdiscursivo, mediante el que el texto literario dialoga con disciplinas artísticas tan diferentes como la pintura, la escultura, la música o la cinematografía, alberga además una funcionalidad narratológica estrechamente relacionada con el recuerdo personal o el legado memorístico perteneciente a la colectividad humana. El lenguaje icónico además presagia, anuncia, y en ocasiones acompaña en algunas páginas consolianas, el devenir de los acontecimientos narrativos con la evidente finalidad de intensificar su magnitud y ampliar su alcance significativo.

\section{Bibliografía}

ADAMO, G. (ed.) (2006). La parola scritta e pronunciata: Nuovi saggi sulla narrativa di Vincenzo Consolo. San Cesario di Lecce: Manni.

ALBERTOCCHI, G. (2005). "Dietro il Retablo. Addio Teresa Blasco, addio Marchesina Beccaria”. Leggere Vincenzo Consolo. Quaderns d'Italià 10: 95-111.

ARQUÉS, R. (2005). "Teriomorfismo e malinconia. Una storia notturna della Sicilia Nottetempo, casa per casa”. Leggere Vincenzo Consolo. Quaderns d'Italià 10: 79-94.

CASTRO, Á. 1996 (1954). La realidad histórica de España. México: Porrua.

CONSOLO, V. 1990a (1988). Le pietre di Pantalica. Milán: Oscar Mondadori.

CONSOLO, V. (1990b). "La cuna del sogno di Vincenzo Consolo" en Nuovo cinema Paradiso. (Giuseppe Tornatore). Palermo: Sellerio editore: 165-171.

CONSOLO, V. (1993a). Fuga dall'Etna. La Sicilia e Milano, la memoria e la storia. Roma: Donizzeli editore.

CONSOLO, V. (1993b). Requiem per le vittime della mafia. Palermo (Italia); São Paulo (Brasil): Renzo y Rean Mazzone editori; Italo-Latino-Americana Palma. CONSOLO, V. 1994a (1992). Nottetempo, casa per casa. Milán: Oscar Mondadori. CONSOLO, V. (1994b). L'olivo e l'olivastro. Milán: Arnoldo Mondadori.

CONSOLO, V. 2000a (1987). Retablo. Milán: Oscar Mondadori.

CONSOLO, V. 2000b (1998). Lo spasimo di Palermo. Milán: Oscar Mondadori. CONSOLO, V. 2001a (1980). "Un giorno come gli altri” en Racconti italiani del Novecento. (3 vols.). (Ed. de Enzo Siciliano). Milán: Mondadori. III: 392-403. CONSOLO, V. 2001b (1999). Di qua dal faro. Milán: Oscar Mondadori. 
CONSOLO, V. 2001c. "Vincenzo Consolo. Letteratura e arte figurativa”. <http:// www.italialibri.net/interviste/consolo/consolo61/html>. (Consultado el 8 de mayo de 2014).

CONSOLO, V. (2002). Oratorio. (Catarsi e L'ape Iblea). Lecce: Manni.

CONSOLO, V. 2004 (1976). Il sorriso dell’ignoto marinaio. Milán: Oscar Mondadori.

CONSOLO, V. 2008 (1963). La ferita dell'aprile. Milán: Oscar Mondadori.

CONSOLO, V. (2013). Esercizi di cronaca. Palermo: Sellerio Editore.

CUBILLO PANIAGUA, R. (2013). "La intermedialidad en el siglo XXI". <http:// historia. fcs.ucr.ac.cr/dialogos.html/index.php/article/view/8444/11465>. (Consultado el 26 de enero de 2016).

CUEVAS, M. Á. (2005). "UT Pictura: el imaginario iconográfico en la obra de Vincenzo Consolo”. Leggere Vincenzo Consolo. Quaderns d'Italià 10: 63-77.

FRACCHIOLA, J. (2008). "Entrevista a Vincenzo Consolo" en La pasión por la lengua. Vincenzo Consolo. (Ed. de Irene Romera Pintor). Valencia: Consejería de Educación: 117-135.

MACK SMITH, D. (1970). Storia della Sicilia medievale e moderna. (3 vols.). Bari: Laterza: Vol. II. Il Risorgimento 1837-1860.

PASCALE, V. (2006). Lo sguardo e la storia: Il sorriso dell'ignoto marinaio. Bolonia: Vecchiarelli.

PARAZZOLI, F. (1998). "L'isola perduta di Vincenzino” en Il gioco del mondo. Dialoghi sulla vita, i sogni, le memorie con Lalla Romano, Vincenzo Consolo, Luciano De Crescendo, Giuseppe Pontiggia, Susanna Tamaro, Antonio Tabucchi, Lara Cardella, Gina Lagorio, Alberto Bevilacqua, Luce D'Eramo. Cinisello Balsamo (Milán): San Paolo: 23-33.

PUGLISI, S. (2008). Soli andavamo per la rovina: saggio sulla scrittura di Vincenzo Consolo. Roma: Bonanno.

RAJEWSKY, I. (2005). "Intermediality, Intertextuality, and Remediation: A literary Perspective of Intermediality”. <http://cri.histart.umontreal.ca/cri/fr/intermedialites/p6/pdfs/p6_rajewsky_text.pdf. (Consultado el 26 de enero de 2016).

SIINO, P. (1980). "Una pagina sconosciuta della rivoluzione siciliana del 1860. I fatti di Alcara Li Fusi”. <http://www.amiciziafraipopoli.org/documentisiialcara.htm>. (Consultado el 8 de febrero de 2014).

TRAINA, G. (2001). Vincenzo Consolo. Fiesole: Cadmo.

VAZZANA, S. (1994). “Nottetempo, casa per casa” en Omaggio a Vicenzo Consolo. (Ed. de Giuseppe Saja). Cefalù: Fondazione Culturale Mandralisca: 35-52. 